Berit Bungum is associate professor at Department of Physics at The Norwegian University of Science and Technology (NTNU) in Trondheim. She holds a master's degree in physics and a doctoral degree in technology education. She now works with physics teacher education at NTNU.

\title{
Images of physics: an explorative study of the changing character of visual images in Norwegian physics textbooks
}

\begin{abstract}
Images are important elements of the communication of physics in textbooks. This paper presents an explorative study of visual images in a sample of nine different Norwegian physics textbooks from 1943 till present. Analysis makes use of the dimensions content specialization, framing and formality. A set of five modes of imaging physics, that also takes characteristics of physics as a discipline into account, is constructed. A meta-analysis of transitions and contrasts between the modes represented in textbooks is then presented in a historical perspective. It is found an increased content specialisation during the time period investigated, which involves a shift from realistic to conventional images. This is associated with an altered focus from experiments to models of physics. In newer textbooks, realism is rather present through images of real scientists at work and through pedagogical models. Based on analysis of framing in images, it is argued that the role of the learner is hence altered from a potential scientist to the one of a consumer of the products of science. Further, it is shown how pedagogical models common in newer textbooks may entail an under-communicated abstraction, where the content specialisation is low while the formality of the image remains high.
\end{abstract}

\section{INTRODUCTION}

Textbooks comprise a fundamental component of teaching a school subject. A range of studies indicates that teachers to a high degree make use of the textbook in their planning and teaching (see Nelson, 2006), even in a time where other sources of information are easily available. Hence textbooks are important for the collective construction of the subject's character and identity, and constitute a shared foundation of knowledge and valid approaches to the subject for teachers and pupils.

Textbooks are, however, not merely simplified version of consensus knowledge in the scientific field. They are rather re-contextualisations of this knowledge according to the organising principles, prevailing conventions and legitimate ideologies of the school subject (Dimopoulos, Koulaidis \& Sklaveniti, 2003). Since textbooks are multimodal texts (Lemke, 1998), this re-contextualisation is made through an interplay between various modes of representation, where visual images play an important role.

This paper reports a study of visual images in a sample of Norwegian physics textbooks from 1943 till present. It investigates the ways in which images communicate physics to the learner and how they engage the learner in physics by visual means. For this purpose a set of modes of imaging 
physics is constructed. The approach is mainly explorative, yet the study also gives an historical account of changes that can be traced during the time period investigated. Some features of the interplay between realistic representations and abstractions communicated in images are then discussed, in particular with regards to the use of pedagogical models used in textbooks.

\section{CONCEPTUAL TOOLS FOR ANALYSIS OF IMAGES}

Images are a form of communication. According to Kress and van Leeuwen (1996), this communication can be described in terms of concepts corresponding to linguistic grammatical schemes, as a "visual semiotic". In their thorough examination of the language of visual images, Kress and van Leeuwen describe this semiotic in terms of narrative and conceptual representations, participants and processes in images.

Narrative representations are dynamic and involve participants and processes in an unfolding of some action or event, denoted narrative processes. "Participants" may be people acting in the world, but also other material entities, or symbols representing them. Narrative representation may be naturalistic images portraying an observable situation, but it may also be more abstract representations.

Conceptional representations expose participants in a less dynamic way. They communicate their more generalized essence, meaning or characteristics. The processes involved in conceptual representations may arrange participants according to some taxonomy (classificational processes), relate them to each other in terms of a part-whole structure (analytical processes) or place participant in a setting of conventional symbols in order to communicate what the participant means or is (symbolic processes).

Based on this work by Kress and van Leeuwen, Dimopoulos et al. (2003) provides a framework for analysing visual images in science textbooks. They also build on Bernstein's work on characteristics of knowledge and power in school subjects (Bernstein, 1971), and Halliday's work on language in science teaching (Halliday, 1996). In their framework, the dimension content specialisation makes a link to Bernstein's concept of classification. Classification in Bernstein's terms denotes the strength of boundaries between knowledge elements. Dimopoulos et al. use this concept by characterising the relationship between the specialised techno-scientific knowledge of the field and the everyday knowledge associated with the same field. In the case of visual images, high degree of content specialisation implies a strong boundary, or difference, between how the phenomenon is represented in the image and how it is more directly perceived by human senses. Strong content specialisation is associated with extensive use of conventions, and hence these images are denoted conventional. Images denoted realistic, represent the phenomenon in ways closer to human perception and hence entail a weaker content specialisation. In-between these two, we find hybrids of conventional and realistic images.

The second dimension, framing, regards the involvement of the reader in the social-pedagogical relationship constituted by the image. In Bernstein's terms, "framing" denotes the strength of the boundary between what may and what may not belong to the pedagogical relationship (Bernstein, 1971). Hence framing concerns the issue of power in defining the content of the communication. With regards to visual images, Dimopoulos et al. (2003) use the concept of framing for characterising the boundary the image creates towards the reader, in the sense that weak framing means that readers are treated as subjects having social power and being able to get actively involved in the pedagogic procedure the image facilitates. They relate this specifically to the design of the image in terms of distance and the horizontal angle of shot. A design inviting the reader into a virtual involvement with objects or in a social event is associated with high degree of involvement and hence weak framing. Strong framing means that angles and distances invite the reader as an observer yet not as a subject being actively involved. 
Finally, formality denotes the degree of abstraction in the image. Low formality means that the meaning communicated by the image is restricted to the concrete features of what it exposes. High formality is associated with attempts to capture the deeper and more general essence of what is exposed in the image, rather than the variability of external features and contextualisation of objects or phenomena. This may be done by a reduced articulation, the presence of techno-scientific codes and by absence of context, at its extreme in terms of generalised graphs and formulas with strong mathematical formalism. However, as will be shown through the analysis in this paper, realistic representations in very concrete contexts may also entail a high formality due to its specific purpose in the text.

\section{THE STUDY}

The sample of the study consists of nine Norwegian physics textbooks for secondary school published in the period from 1943 till present. Most of them are written for upper secondary school level ("gymnas"), but some are intended for physics teaching at lower levels ("ungdomsskole" and the former "realskole"). The selection includes the most commonly used textbooks in the time period. Some of these are published in numerous editions and used in schools for several decades. The two books from 1943 are $4^{\text {th }}$ and $11^{\text {th }}$ edition respectively, and hence the sample covers the widely used textbook for about a century. A list of the textbooks is given at the end of this paper.

The analysis is limited to the parts of the books dealing with electricity and magnetism, in order to avoid effects of changes in the curriculum's prescriptions of topics during the time period chosen. The topic is chosen because it is well represented in physics textbooks in the entire time span investigated, and provides for a range of experimental and theoretical approaches to be manifested in images.

Analysis of images was undertaken by characterising individual images by means of the dimensions provided by Dimopoulos et al. (2003). A set of 5 main modes of imaging physics was then constructed inductively from the images in the sample of textbooks. The construction of modes makes use of the presented dimensions, but also includes more specific features of physics communicated in the images. These modes are briefly presented in the following. Although they do provide for quantitative analyses of images in textbook, the subsequent presentation and discussion of results rather concentrate on contrasts and transitions between the modes identified, based on a qualitative meta-analysis in a historical perspective.

\section{MODES OF IMAGING PHYSICS}

The following modes of representing physics in visual images were constructed based on analysis of images in the sample of textbooks:

\section{Mode 1: involving the learner in experiments:}

These images are characterised by being realistic with weak framing, high content specialisation but low formality. The image together with the verbal text presents how a specific experiment is undertaken, and what will happen. The result of the experiment is then used for introduction and discussion of physics concepts or relationships. This educational content is often presented as part of explanations to what happens in the experiment. Nevertheless, the approach underlines the experimental basis of physics and that this forms the foundation on which theories in physics are based.

\section{Mode 2: Visualizing a world of models:}

A great deal of images in physics textbooks intend to represent theoretical models of physical phenomena by visual means. They may be seemingly realistic, but still represent conventions in 
how the world is perceived in physics. Formality may be high in cases where the images present generalized inscriptions (Latour \& Woolgar, 1979) in terms of graphs and relationships expressed in mathematical equations. Images of this mode demonstrate for the learner that physics is about representing the world in a different way than how it is usually perceived, i.e. by the use of models, and that learning physics means to learn to see the world this way.

\section{Mode 3: Showing the visual appearance of objects:}

This mode of imaging in physics textbooks presents the actual visual appearance of objects. It embraces realistic images of objects in themselves, often free of contexts such as experiments or otherwise. The purpose is to familiarize the learner with specific objects important in physics.

\section{Mode 4: Translating between representations:}

A hybrid of the conventional and realistic images in modes 2 and 3 gives rise to a specific mode of visualisation, creating links between the actual appearance of objects or systems and how features of these are represented in the models used in physics. The role of the image in the text is hence to perform a translation between the two ways of representing the world.

\section{Mode 5: Demonstrating relevance and use:}

These images demonstrate for the learner how the subject matter presented has relevance and is used in society and daily life by presenting objects and systems well known to the learner. They contribute to a reduction in formality and weakening of framing in the text as a whole, but are often independent of the flow of other text.

\section{FROM EXPERIMENTS TO MODELS: REALISTIC AND CONVENTIONAL REPRESENTATIONS}

Images of Mode 1, involving the learner in experiments, are well represented in the sample, and in particular in some older textbooks in the sample. They provide naturalistic drawings of how relatively simple experiments are conducted. A typical example from 1943 is given in Figure 1a, showing how electric current is produced in one inductor due to the magnetic field from another inductor and their relative movement. The image is narrative in the sense that the small arrows show directions of currents in the two inductors. The image is otherwise entirely realistic, with sufficient detail for the reader to perform - or at least to get the sense of performing - the experiment. Since the result of the experiment is given in the accompanying text, the educational purpose appears to be conceptual knowledge such as the electromagnetic relationships represented in the example, rather than the experiment itself.

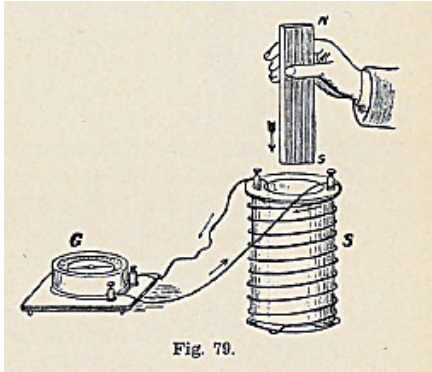

Figure 1a. Isaachsen, 1943.

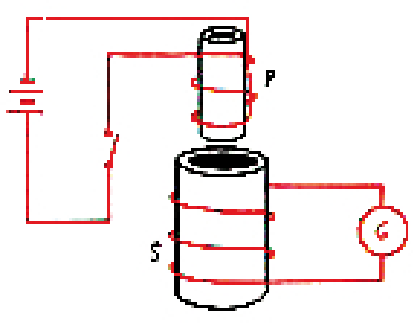

Figure 1b. Isaachsen, 1963.

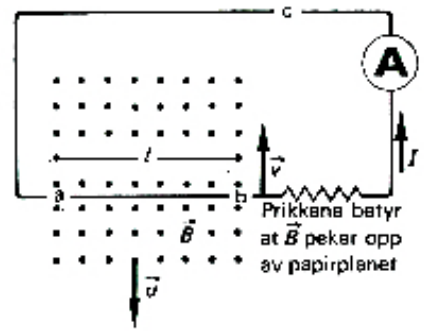

Figure 1c. Øgrim, Ormestad \& Lunde, 1972. 
Figure 1b from 1963 shows the same experiment as a hybrid between realistic and conventional representation, while Figure 1c (1972) is an entirely conventional image. The latter image represents the theory of induction in a more generalised form, and the reader gets no idea of what physically produces the magnetic field, or the fact that for experimental purposes a coil is more efficient than a single current loop. Correspondingly, the relative movement is signified by means of the conventional $\mathrm{u}$-vector. What causes this movement is, however, absent, in contrast to the way the human hand in Figure 1a provides the more concrete source for movement. The progression from Figure 1a through $1 \mathrm{~b}$ to $1 \mathrm{c}$ represents a transition from Mode 1 of imaging physics to Mode 3, yet the physics content of the image appear to be the same. The transition involves a clear increase in content specialization, that is, increased use of conventions. With regards to the nature of physics communicated, it develops from telling the narrative of an experiment towards visualising a model in terms of relationships between conceptual entities (see Ogborn, Kress, Martins, \& McGillicuddy, 1996). Yet the results are not unambiguous, the analysis of images in the sample of textbooks indicates that this shift constitutes a trend in the textbooks from early $20^{\text {th }}$ century and onwards.

\section{INVOLVING THE LEARNER IN PHYSICS: FRAMING IN IMAGES}

The shift from images unfolding experiments towards those communicating more abstract models described above does not mean that the experimental base of physics is absent in newer textbooks. It is, however, represented in a different way. This difference can be interpreted in terms of how Dimopoulos et al. (2003) have employed Bernstein's concept of framing in the case of visual images.

Figure 2a shows an experimental set-up with similar characteristics as the one in Figure 1a), typical of Mode 1. Both images present the experiment with weak framing towards the reader, as the perspective and richness of detail make the objects appear to the reader the way it would look if the experiment was performed by the reader him- or herself. Note that this also apply to the hand shown in Figure 1a); it appears as it would do if it belonged to the reader (provided the reader is male as well as right-handed, anticipations consistently made in the older textbooks). Except for such occurrences of sole hands, these images - common in older textbooks - rarely present humans as participants. The main participant in the image appears to be the viewer, as the image together with the text has the function of an instruction of how the experiment can be performed. Narrative processes are hence taking place in a virtual way between the experimental setup and the viewer.
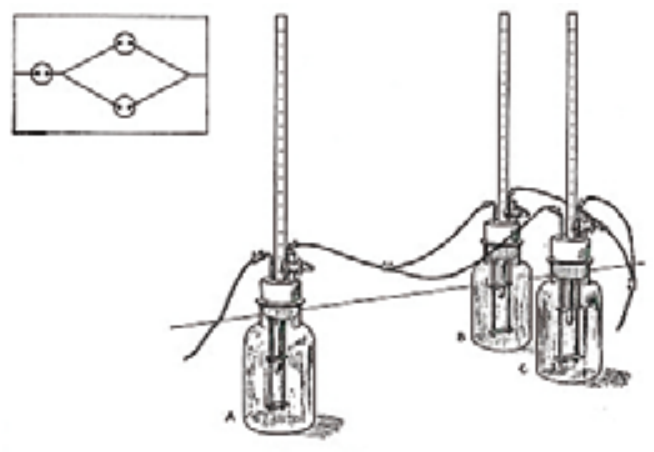

Figure 2a. Bruun \& Devik, 1943.

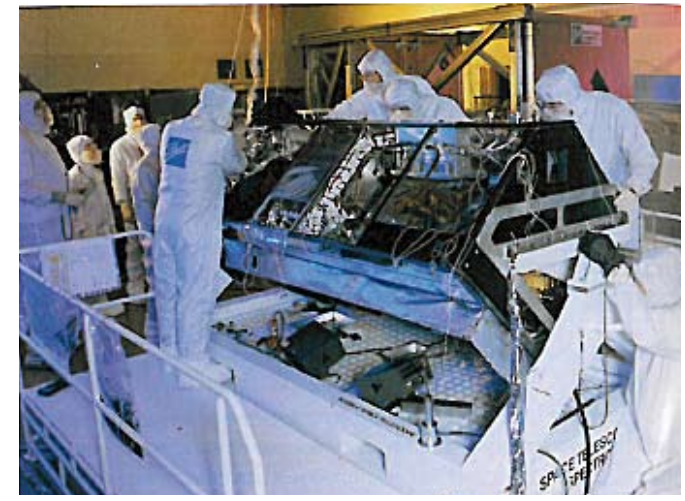

Figure 2b. Callin, Pålsgård, Stadnes \& Tellefsen, 2007. 
The framing is much stronger in Figure $2 b$ ), where the distance to the reader makes such virtual involvement with the equipment impossible. The reader is rather turned into an observer of scientists at work, with no sense of control of what's going on. Since we are not told the story of what takes place in this experiment, the processes in the image is rather symbolic than narrative (see Kress \& van Leeuwen, 1996). The image communicates that these people are scientists - not what they do. This type of images with humans at work with research in physics has become more common in newer textbooks. The purpose is doubtless to provide the learner with a more realistic image of how real science is taking place, in this case related to the Hubble telescope. However, what is lost on the way is the learner's sense of participating in the experiments as physics narratives.

While older textbooks invite the learner to participate in experiments, newer textbooks appear to provide involvement of the reader by means of weak framing of images in other settings, as "Demonstrating relevance and use" (Mode 5). These images often display the technological application of physics in society, and hence demonstrate for the learner the relevance of the subject. One example is given in Figure 3, where the use of light-emitting diodes in traffic light is exposed. This type of images displays objects already familiar to the reader, in order to bring attention to how these familiar objects make use of physics. This creates a link between the learner's daily experiences and the physics content presented. The object's working principles, however, are rarely discussed. This makes a contrast to traditional physics images as the one in Figure 4, where the working principle of an instrument for electrical measurement is illustrated by a hybrid representation where arrows represent forces and movement, magnetic field and current respectively. Due to this complexity and the higher content specialisation, the narrative content of the image clearly requires some effort to comprehend. In addition, both the instrument and the principles through which it is explained might appear as unfamiliar to the learner. Images of objects aiming at demonstrating relevance and use, as the traffic light in Figure 3, are on the contrary most often purely realistic and the objects are clearly recognisable to the learner. Hence the image contributes to a reduction in formality and weakening of content specialisation as well as framing in the text as a whole, although they may play a marginal (in a literary sense) role in text.

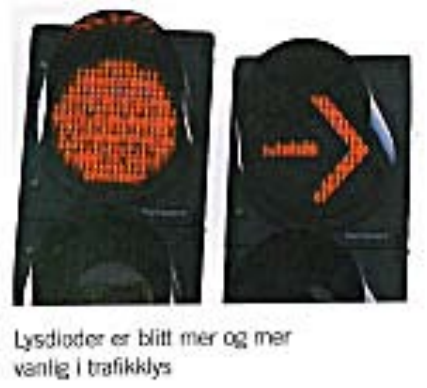

Figure 3. Jerstad, Sletbak, Grimnes \& Renstrøm, 2007. The caption reads: "LEDs have become more and more common in traffic lights".
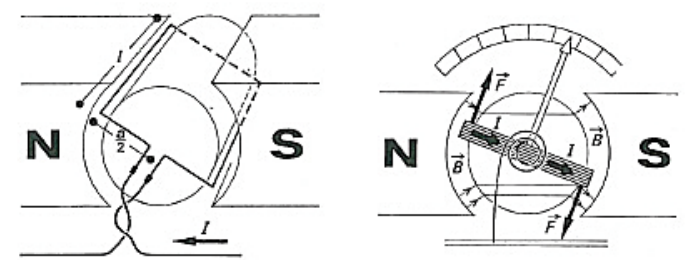

Figure 4. Øgrim, Ormestad \& Lunde, 1972.

\section{REALISM AND UNDER-COMMUNICATED ABSTRACTION: FROM SCIENTIFIC OBJECTS TO MENTAL TOOLS}

As physics concerns knowledge of natural phenomena, textbooks in general contain a range of naturalistic images. A great deal of these, however, displays human-made objects, described as Mode 3. Some are technological objects where the learning content is the working principles of those. It has been argued elsewhere that school physics during the $20^{\text {th }}$ century developed from a "workshop subject" with focus on technical tools and equipment towards a "scientific subject" emphasising 
concepts and theoretical models (Olsen, 2004). However, investigation into images in older textbooks reveals that many of the tools described by means of realistic images are of scientific rather than technological use. One example is given in Figure 5, showing measurement of current from an influence machine. This "machine", appearing in most physics textbooks until the 1960s, was used for experiments and did not otherwise have any practical use. Hence the subject was not less "scientific" but the way of being scientific seems to have undergone a change from realistic images of objects of scientific significance (Mode 3) towards images visualising the theoretical products of science and aiming at conceptual understanding (Mode 2). An image emphasising the latter is shown in Figure 6, where Kirchhoff's rule of continuity of potential difference is shown by graphical means. This conventional image and the accompanying text deal with scientific principles, while the ways in which this is observed, or how the circuit actually look, is left open.

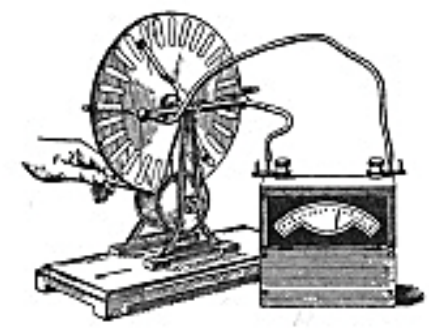

Figure 5. Isaachsen 1963.

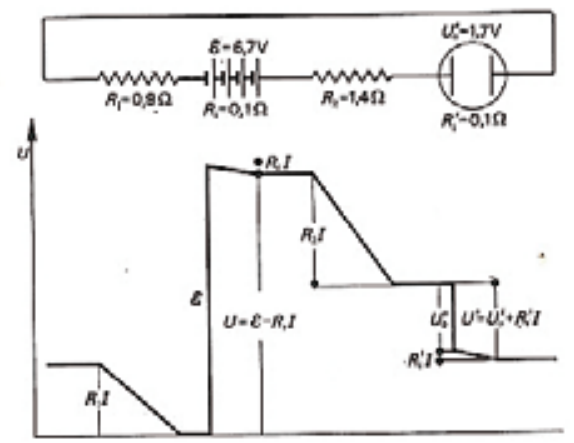

Figure 6. Øgrim, Ormestad \& Lunde, 1972.

(Identical image appears in Øgrim, Ormestad, Lunde, Jerstad \& Sletbak, 1990.)

As realism in terms of experimental equipment seems to have to some extent been replaced with scientific models, a subtle kind of realism has risen again through images illustrating pedagogical models, aiming at supporting understanding of the models of physics. In the sample of textbooks, these images are rare before the 1960s. Figure 7 shows an example from 1968, where mechanical models of voltage (difference in potential) and electric current are presented. The realism in the images resembles the earlier realistic images of experimental set-ups (Mode 1), but the scientific learning objective is here not the illustrated mechanical experiments themselves but rather how these model the more abstract concepts of electric voltage and current. In newer textbooks even photographs play this role of communicating an abstract content by very concrete means. For example, the ski lift in Figure 8 has nothing to do with winter sports, but is intended to give the reader an idea of what Kirchhoff has to tell us about electric potential around a closed circuit; that is, identical content as in Figure 6. The familiar and very concrete ski lift is intended as a mental tool in order to understand the more abstract principles of voltage in an electric circuit.

The main difference between the two ways of imaging Kirchhoff's rule is the higher content specialisation in Figure 6, as the reading of the graph requires specialized knowledge of the language of physics, while the ski lift shown in Figure 8 is a familiar object to most (Norwegian) youth. The formality of the two images, however, is equally high. In Figure 8 the formality lies in the transition between the object explicitly shown (ski lift) to the one the image represent (electric circuit). In order to comprehend the intended content of this image, the reader needs to extract key ideas from one concrete context and transfer them to another. Taken the intention into account, the image is not realistic but entails an abstraction that is under-communicated because conventions for the abstraction are not presented. 


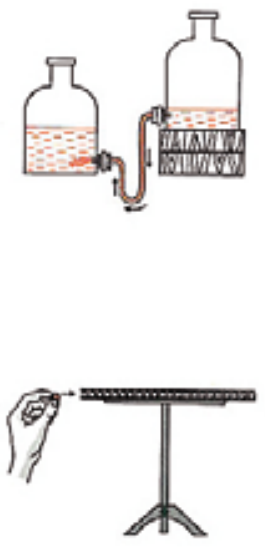

Figure 7. Arnljot, 1968.
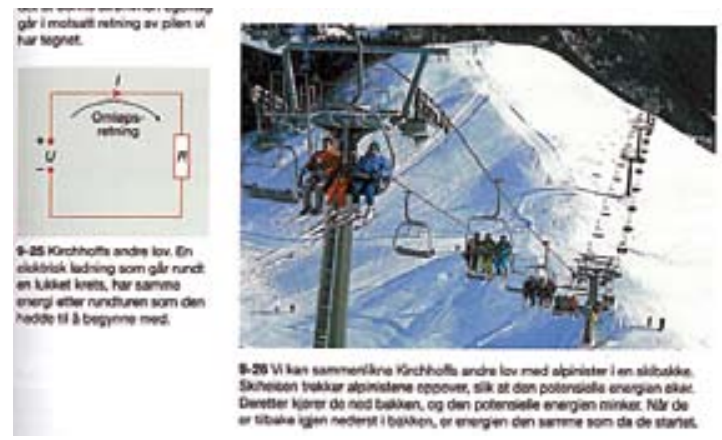

Figure 8. Callin, Pålsgård, Stadnes \& Tellefsen, 2007.

\section{CONCLUSION}

Other studies of physics textbooks have suggested that they are fairly stable over time (Martins, 2007). This is also true for the textbooks in the present study, and for the kind of images used. However, it has also been shown that important shifts can be detected through the time period investigated

While textbooks from the first half of the $20^{\text {th }}$ century to a high degree presented both scientific objects and experiments in realistic ways as a foundation for knowledge in physics, newer textbooks tend to present the same subject matter with higher content specialisation by means of conceptual entities and generalised models. Hence use of conventions seems to have replaced experimental detail to some extent. This also involves that narrative processes between the viewer and virtual objects in the image have been replaced by narrative processes between conceptual entities in order to communicate features of scientific models in physics.

This shift in the characteristics of images does not mean that today's textbooks on the whole appear as more abstract in their images. Realism seems to have risen again in two ways; firstly through images of real scientists at work and the use of physics in familiar technological objects, secondly through pedagogical models intended as mental tools to support the learner's understanding of abstract content. Images of the former kind give a more realistic view of real research in physics and its products than the simpler experiments presented in the older textbooks. The weak framing in images of experiments is replaced by weak framing towards the reader as a consumer of technological products of science. A consequence of this development seems to be that the learner's role in the textbook is transferred from a potential scientist to the one of an observer or consumer of physics.

The focus on models in science education is well-known (Gobert, 2000) and reasonable due to their importance in modern science. Many studies have, however, shown that pupils have considerable problems in understanding abstract models (Pintó \& Amettler, 2002). Awareness of these problems might have influenced the development towards increased use of pedagogical models, which in turn are associated with certain challenges.

It is shown in this study that pedagogical models may involve an under-communicated abstraction. Images using concrete analogies for illustrating abstract content are apparently realistic and present subject matter with a lower content specialisation than the more generalised models. 
However, they entail a high formality in that specific characteristics of the concrete context are to be mentally translated to a very different context. As Roth, Tobin and Shaw (1997) have conjectured, such translations between ontologically distinct re-presentations might not be transparent to physics newcomers, and may therefore impede their understanding and learning in the subject.

In general, images in physics textbooks are complex stories, and require a high reading proficiency to be comprehended. This may be one reason why physics is seen as more difficult and more theoretical than other subjects (Duit, Niedderer, \& Schecker, 2007), and should be a matter of further exploration for teachers, textbook writers and science educators.

\section{TEXTBOOKS USED IN ANALYSIS}

The textbooks are given in chronological order.

Bruun, S. \& Devik, O. (1943). Fysikk for realskolen og de to første klassene av gymnaset, 4. utgave. Oslo: Olaf Nordlis Forlag.

Isaachsen, D. (1943). Lcerebok i Fysikk for Realgymnaset. 11. utgave. Av: G. Holtsmark. Oslo: H. Aschehoug \& Co (W. Nygaard).

Isaachsen, D. (1963). Lorebok i Fysikk for Realgymnaset. II. 16. utgave ved J. Holtsmark. Oslo: H. Aschehoug \& Co (W. Nygaard).

Arnljot, I. (1968). Fysikk for ungdomsskolen. Oslo: Cappelen.

Bruun, S. \& Devik, O., (1970): Lcerebok i fysikk for reallinjen og naturfaglinjen. Revidert utgave av H. Råstad \& H. Viervoll. Oslo: Olaf Norlis Forlag.

Øgrim, O., Ormestad, H., Lunde, K. (1972): Rom, Stoff, Tid. Fysikk for gymnaset. Bind 3, elektrisitet, atomfysikk. Oslo: J. W. Cappelens Forlag AS.

Øgrim, O., Ormestad, H., Lunde, K., Jerstad, P, \& Sletbak, B. (1990): Rom, Stoff, Tid. 2FY. Oslo: Cappelen.

Callin, P., Pålsgård, J., Stadsnes, R. \& Tellefsen, C. W. (2007). ERGO. Fysikk 1. Oslo: Aschehoug. Jerstad, P., Sletbak, B., Grimnes, A. A. \& Renstrøm, R. (2007): Rom, Stoff, Tid. Fysikk 1. Oslo: Cappelen.

\section{REFERENCES}

Bernstein, B. (1971). On the Classification and Framing of Educational Knowledge. In M. F. D. Young (Ed.), Knowledge and Control. New Directions for the Sociology of Education. London: Collier MacMillan.

Dimopoulos, K., Koulaidis, V., \& Sklaveniti, S. (2003). Towards an Analysis of Visual Images in School Science Textbooks and Press Articles about Science and Technology. Research in Science Education, 33, 189-216.

Duit, R., Niedderer, H., \& Schecker, H. (2007). Teaching Physics. In: S. K. Abell \& N. G. Lederman (Eds.), Handbook of Research on Science Education (pp. 599-629). New Jersey, London: Lawrence Erlbaum Associates.

Gobert, J. D. (2000). Introduction to model-based teaching and learning in science education. International Journal of Science Education, 22 (9), 891-894.

Halliday, M. A. K. (1996). On the language of physical science. In: M. A. K. Halliday \& J. R. Martin (Eds.). Writing science: Literacy and discursive power (p. 54-68). London: The Falmer Press.

Kress, G., \& van Leeuwen, T. (1996). Reading Images. The Grammar of Visual Design. London and New York: Routledge.

Latour, B. \& Woolgar, S. (1979). Laboratory Life. The Social Construction of Scientific Facts. Sage Library of Social Research, Vol. 8. Beverly Hills / London: Sage Publications. 
Lemke, J. L. (1998). Multiplying meanings: visual and verbal semiotics in scientific texts. In J. R. Martin, \& R. Veel (Eds.), Reading Science: Critical and Functional Perspectives on Discourse of Science (pp. 87-113). London: Routledge.

Martins, I. (2007): Stability and change in the Physics textbook discourse. Paper presented at the ESERA conference, Malmö, 2007. Available online from http://195.178.227.107/esera/Files/302.doc

Nelson, J. (2006). Hur används läroboken av lärare och elever? NorDiNa, 4, 16-27.

Ogborn, J., Kress, G., Martins, I., \& McGillicuddy, K. (1996). Explaining Science in the Classroom. Buckingham, Philadelpia: Open University Press.

Olsen, R. V. (Ed.) (2004). Fysikk for framtiden: en drøfting av og grunnlag for framtidig loereplan $i$ fysikk. Oslo: Norsk Fysikklærerforening.

Pintó, R., \& Amettler, J. (2002). Students' difficulties in reading images. Comparing results from four national research groups. International Journal of Science Education, 24 (3), 333-341.

Roth, W.-M., Tobin, K., \& Shaw, K. (1997). Cascades of inscriptions and the re-presentation of nature: How numbers, tables, graphs, and money come to re-present a rolling ball. International Journal of Science Education, 19 (9), 1075-1091. 